\title{
Formulation and in vitro / in vivo Evaluation of Novel Biodegradable Microspheres for Treatment of Hormone Responsive Cancers
}

\author{
Suhas Marutirao Kakade ${ }^{1,2 *}$, Dehghan Mohamed Hassan ${ }^{1}$ \\ 'Department of Pharmaceutics, Y. B. Chavan College of Pharmacy, Dr. Rafiq Zakaria Campus, Aurangabad, Maharashtra, INDIA. \\ ${ }^{2}$ Wockhardt Research Centre, D-4, MIDC Area, Chikalthana, Aurangabad, Maharashtra, INDIA.
}

\begin{abstract}
Objectives: The present work relates with developing long acting controlled release poly(DL-lactide-co-glycolic acid) (PLGA) microspheres of Goserelin acetate for treatment of breast and prostate cancer. Methods: Microspheres were prepared by using biodegradable polymers PLGA 50:50 and PLGA 75:25 employing modified emulsification method by using static mixer. Evaluate the effect of process and formulation variables on the characteristics of microspheres were studied. Particle size distribution, surface morphology, encapsulation efficiency, in vitro drug release and in vivo drug release profile in Wistar rats were investigated. Results: Preparative variables such as concentrations of stabilizer, drug-polymer ratio, stirring rate and ratio of internal to external phases were found to be important factors for the preparation of Goserelin acetate loaded PLGA microspheres. These changes were also reflect in vitro and in vivo drug release profiles. The result indicated that the morphology of Goserelin acetate PLGA microspheres presented as spherical shape with smooth surface, homogenous drug distribution and the particle size distributed from 88.11 to $116.78 \mu \mathrm{m}$. In vitro and in vivo release profile showed controlled initial burst release followed by one month sustained release profile of the Goserelin acetate
\end{abstract}

loaded PLGA microspheres. Conclusion: The process and formulation variables could be effectively modified to achieve the desired characteristics and one month sustained release of Goserelin acetate loaded biodegradable polymeric microspheres showed potential for treatment of hormone responsive cancers.

Key words: Breast cancer, Prostate cancer, Goserelin acetate, Microspheres, poly(D, L-lactide-co-glycolide).

\section{Correspondence}

\section{Mr. Suhas Marutirao Kakade,}

'Department of Pharmaceutics, Y. B. Chavan College of Pharmacy, Dr. Rafiq Zakaria Campus, Aurangabad-431001, Maharashtra, INDIA.

${ }^{2}$ Wockhardt Research Centre, D-4, MIDC Area, Chikalthana, Aurangabad-431001, Maharashtra, INDIA.

Phone: +919423714153

Email: suhaspharma@yahoo.com;

ORCID: http://orcid.org/0000-0002-3729-5303

DOI: 10.5530/ijpi.2020.2.34

\section{INTRODUCTION}

The basic principle for controlled drug delivery system is to change the biopharmaceutical, pharmacokinetics and pharmacodynamics properties of pharmacologically active moieties by using novel drug delivery systems or by modifying the molecular structure and physiological parameter inherent in preferred route of administration. ${ }^{1}$ The primary goals of controlled drug delivery are to ensure safety and to improve efficacy of drugs as well as patients compliance. ${ }^{2}$ This is achieved by higher management of plasma drug levels and fewer frequent dosing. In general, the dosing interval is also magnified either by modifying the drug molecule to decrease the rate of elimination $\left(\mathrm{K}_{\mathrm{cl}}\right)$ or by modifying the release rate of a dosage form to decrease the rate of absorption $\left(\mathrm{K}_{\mathrm{a}}\right)$. Both the approaches look for decrease fluctuations in plasma level throughout multiple dosing, permitting the dosing interval to extend while not either over dosing or beneath dosing. ${ }^{3}$

The controlled drug delivery can be designed according to various routes of administration. ${ }^{4}$ Although oral administration of drugs could be wide accepted route of drug delivery, bioavailability of drugs usually varies as a result of gastrointestinal absorption, degradation by first-pass effect and hostile surrounding of gastrointestinal tract. Transdermal administration for percutaneous absorption of drug is limited by the impermeable nature of the stratum corneum..$^{5}$ Therefore, in such situation, the parenteral route is the most viable approach, of the various ways in which biodegradable polymeric microspheres are one of the better means of controlled drug release over a longer period of time to achieve long-term parenteral drug delivery. ${ }^{6}$

Microspheres formulations are particularly well suited for parenteral route of administration and consist of polymeric materials in which active agents are encapsulated at high efficiency. ${ }^{7}$ Biodegradable microspheres are made of biodegradable products, which can be injected with as syringe into the body and once injected, solidify to form a semisolid deposit. ${ }^{8}$ Drug is gradually release on erosion or by diffusion from the particles. These systems offer certain unique advantages, which has sparked people's interest. In addition to ease of use, these include targeted delivery for a site-specific action, longer delivery times, reduced medication dose with corresponding reduction in potential undesirable side effects common to most types of systemic delivery and enhanced patient compliance and comfort. ${ }^{9}$ Poly (glycolic acid) (PGA), poly (lactic acid) (PLA) and its copolymers poly (DL-lactide-co-glycolic acid) (PLGA), have attracted attention due to their remarkable features such as biodegradability, biocompatibility andsafety. ${ }^{10}$

Biodegradable Microspheres are usually prepared by various methods such as Emulsification, Spray drying, Phase separation (Conservation), Solvent extraction, Evaporation base processes and Supercritical technology. ${ }^{11}$ Emulsification extraction method is a common technique for preparation of controlled release biodegradable microparticles. Emulsification is critical step in microencapsulation process and has 
strong impact on the microspheres properties such as particle size distribution, morphology, encapsulation efficiency, drug loading, burst release etc. $^{12}$

The major challenges in biodegradable microspheres are reduced initial burst release and achieve constant release rate. The initial burst release occurs due to the heterogeneous drug distribution and surface morphology of the microspheres appears pores and cracks. ${ }^{13,14}$

Therefore, it is important to understand the effect of the process parameters on the emulsion quality and to control the process accordingly. In present studies, developed the processes to improve understanding of the emulsion production with static mixers. Static mixer consist of motionless mixer elements with cross-bars fitted in a cylindrical tube. Flow pattern in such mixer may be laminar or turbulent. Mixing in these systems is achieved by dividing and re-uniting fluid streams. Unit operations carried out by static mixers are the blending of fluids, heat transfer and solids blending. Static mixers are usually multiphase applications with the blending of a continuous liquid phase and a dispersed phase or immiscible liquid phase. ${ }^{15}$ The numbers of advantages of using static mixer are easily controlled particle size distribution, homogenous drug distribution, higher efficiency, easily scaled up and suited for aseptic manufacturing.

Certain cancers, notably those of the reproductive tract-prostate and testis cancer in men and breast, ovarian and endometrial cancer in women, are described as hormone-dependent cancers. The sex steroid hormones such as androgens, estrogens and progestins play crucial role in both normal development and maintenance of these organs, as well as premalignant and malignant growths. ${ }^{16,17}$

Goserelin acetate is the most widely used drug for the chemotherapy of the prostate and breast cancer and approved by the United States of Food and Drug Administration (USFDA). It acts as a potent inhibitor of pituitary gonadotropin secretion and suppression of luteinizing hormone (LH) and serum testosterone levels. ${ }^{18,19}$

Controlled release drug delivery system based biodegradable Goserelin acetate microspheres for subcutaneous administration to treat hormone responsive cancers such as prostate and breast cancer. It decreases male sex hormone testosterone and female sex hormones estrogen and progesterone, which may stimulate the growth of cancer cell. However in order to effectively improve patient compliance with fewer side effects.

The present work was to design the controlled release biodegradable microspheres of Goserelin acetate by modified emulsification technique using static mixer and evaluate the effects of various process as well as formulation variables were carried out their in vitro and in vivo characterization. The pharmacokinetics studies are essential to determine the exposures of these formulations and to correlate their in vivo exposures with in vitro drug release pattern. Wistar rats were used to perform the in vivo studied. These species are considered to be more appropriate to perform such studies as their disposition profile is close to human.

\section{MATERIALS AND METHODS}

\section{Materials}

Goserelin acetate was purchased from Hemmo Pharmaceutical Private Limited, India. poly(D, L-lactide-co-glycolide) (PLGA)lactide: glycolide ratio, 50:50 (Resomer RG505, Resomer RG504, Resomer RG504H) and lactide: glycolide ratio, 75:25 (Resomer RG750) were purchased from Evonik Roehm Gmbh Germany. Polyvinyl alcohol4-88 (PVA) and Ethyl acetate were supplied by Merck Ltd. All chemicals and reagents used were of injectable grade.

\section{Preparation of microspheres}

Goserelin acetate loaded PLGA microspheres were prepared by emulsification method using static mixer. ${ }^{20}$ (Table 1 and Figure 1).

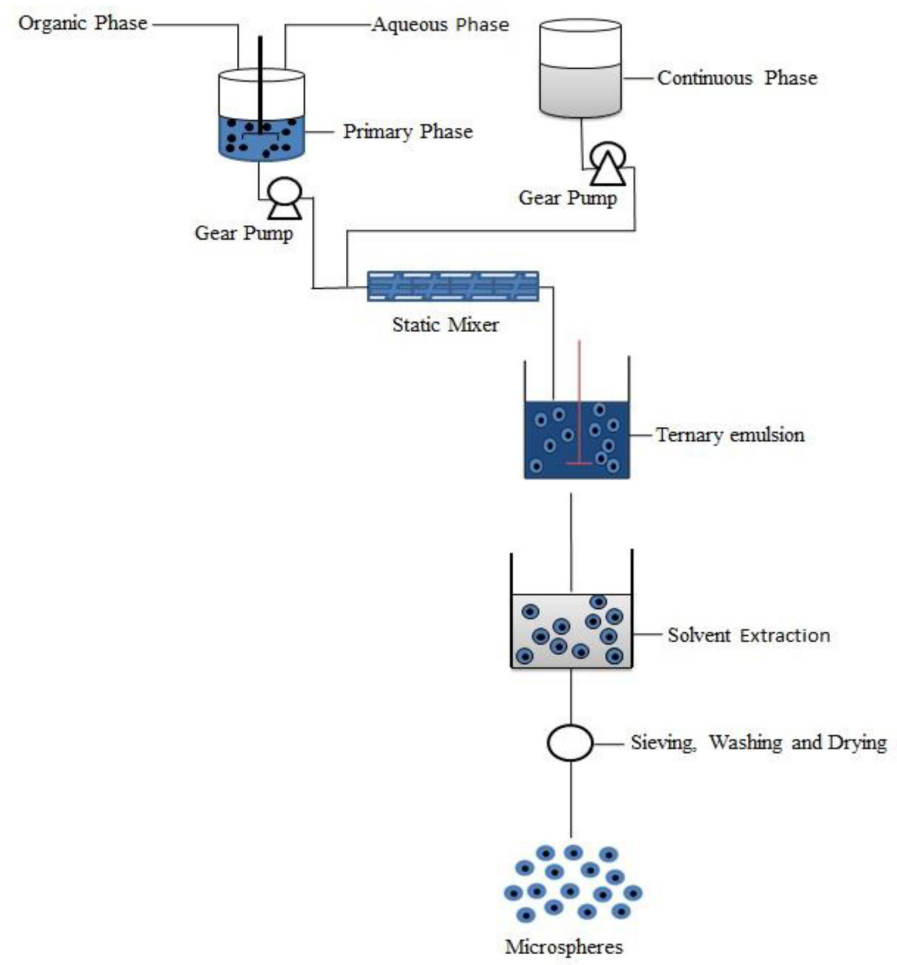

Figure 1: Preparation of microspheres.

Table 1: Composition of Goserelin acetate PLGA microspheres.

\begin{tabular}{|c|c|c|c|c|c|c|c|c|}
\hline \multirow{3}{*}{$\begin{array}{l}\text { Formulation } \\
\text { code }\end{array}$} & \multicolumn{8}{|c|}{ Manufacturing variables } \\
\hline & \multirow{2}{*}{$\begin{array}{c}\text { Goserelin } \\
\text { acetate }(\mathrm{mg})\end{array}$} & \multicolumn{3}{|c|}{ PLGA 50:50 (mg) } & \multirow{2}{*}{$\frac{\text { PLGA 75:25 (mg) }}{\text { RG750S }}$} & \multirow{2}{*}{$\begin{array}{c}\text { Water for } \\
\text { Injection (mL) }\end{array}$} & \multirow{2}{*}{$\begin{array}{l}\text { Ethyl acetate } \\
(\mathrm{mL})\end{array}$} & \multirow{2}{*}{$\begin{array}{c}\text { Primary phase: } \\
\text { continuous phase ratio }\end{array}$} \\
\hline & & RG505 & RG504 & RG504H & & & & \\
\hline M1 & 10 & 90 & - & - & - & 0.5 & 5 & $1: 1$ \\
\hline M2 & 10 & 90 & - & - & - & 0.5 & 5 & $1: 3$ \\
\hline M3 & 10 & 90 & - & - & - & 0.5 & 5 & $1: 5$ \\
\hline M4 & 10 & - & 90 & - & - & 0.5 & 5 & $1: 5$ \\
\hline M5 & 10 & - & - & 90 & - & 0.5 & 5 & $1: 5$ \\
\hline M6 & 10 & - & - & & 90 & 0.5 & 5 & $1: 5$ \\
\hline
\end{tabular}


Preparation of the Primary phase: poly-(DL-Lactide-co-glycolide) was dissolved in ethyl acetate to obtain an organic phase and Goserelin acetate was dissolved in water for injection to obtain an aqueous phase. This aqueous phase emulsified with organic phase using silver son homogenizer at $1000 \mathrm{rpm}$ for $2 \mathrm{~min}$.

Preparation of Continuous phase: Polyvinyl alcohol (1w/v \%) and ethyl acetate was dissolved in water for injection and filter through a $0.22 \mu$ filter.

Preparation of the ternary emulsion (water/oil/water): Primary phase was pumped simultaneously with a continuous phase through a $1 / 4$ inch static mixer at varying flow ratio (1:1, 1:3 and 1:5).

Solvent Extraction: The emulsion was transferred into tank containing water for injection $\left(2^{\circ} \mathrm{C}-8^{\circ} \mathrm{C}\right)$ and mixed for $240 \mathrm{~min}$ for extraction (extraction Ratio $3 \%$ ) of the solvent from the emulsion and hardening of microspheres.

Sieving and drying of the microspheres: Slurry contains microspheres from tank was passed through a $28 \mu \mathrm{m}$ sieve and subsequently a $150 \mu \mathrm{m}$ sieve, washed with water for injection.

Microspheres were collected into drying device and dried at $28^{\circ} \mathrm{C}$ for 16 hrs. Dried microspheres were collected in glass vials and stored at $2-8^{\circ} \mathrm{C}$.

\section{Evaluation of microspheres \\ Microsphere morphology}

The shape and surface morphology of the Goserelin acetate loaded PLGA microspheres were

\section{Particle size analysis}

The volume average particle diameter (Mean size) and size distribution of all Goserelin acetate loaded PLGA microspheres were analysed by a laser diffraction particle size analyser (Mastersizer 2000, Malvern, UK).

\section{Encapsulation efficiency}

The encapsulation efficiency of Goserelin acetate loaded PLGA microspheres was determined by dissolving $55 \mathrm{mg}$ of microspheres in $15 \mathrm{~mL}$ of acetonitrile and make up volume upto $50 \mathrm{~mL}$ with Phosphate buffer $\mathrm{pH}$ 7.4. The solution was filtered through $0.45 \mu \mathrm{m}$ Millex-HV filters and suitable dilution with phosphate buffer $\mathrm{pH}$ 7.4. Goserelin acetate concentration in these samples were measured by reverse phase high performance liquid chromatography (HPLC) using a column $\mathrm{C}_{18}$ column [octadecylsilane (ODS), $150 \times 4.6 \mathrm{~mm}$, pore size $5 \mu \mathrm{m}$, Phenomenex Inc., Japan] and a mobile phase of phosphate buffer $\mathrm{pH}$ 7.4:acetonitrile in ratio of $70: 30 \mathrm{v} / \mathrm{v}$. The flow rate was set at $1 \mathrm{~mL} / \mathrm{min}$. The absorbance values at $220 \mathrm{~nm}$ corresponding to concentration were then evaluated.

To calculate the \% Encapsulation efficiency following equation used.

$$
\begin{gathered}
\text { Drug Loading }(\%)=\frac{\text { Weight of drug in microspheres }}{\text { Weight of microspheres }} \times 100 \\
\text { Encapsulation efficiency }(\%)=\frac{\text { Actual drug loading }(\%)}{\text { Thoretical drug loading }(\%)} \times 100
\end{gathered}
$$

\section{Inherent Viscosity}

Inherent viscosity of Goserelin acetate loaded PLGA microspheres was measuring by using Microostwald viscometer. ${ }^{21}$ Inherent viscosity is calculated as ratio of the natural logarithm of the relative viscosity and the mass concentration of the polymer (C). Approximately $55 \mathrm{mg}$ Microspheres were dissolved in $10 \mathrm{~mL}$ of chloroform. Microostwald viscometer having capillary constant $0.01 \mathrm{~mm}^{2} / \mathrm{s}$ was used. The viscometer was kept in auto rinse mode and allowed $1 \mathrm{~min}$ pretampering wash and then sample analysis was repeated three times by which Kinematic and Inherent viscosities were obtained as

Calculation formula:

$$
\begin{gathered}
\text { Rleative Viscosity } \eta r=\eta S / \eta 0=t_{s} / t_{0} \\
\eta i n h(d l / g)=(\ln \eta r) / C
\end{gathered}
$$

\section{Differential scanning colorimeter (DSC)}

The glass transition temperature ( $\mathrm{Tg}$ ) of Goserelin acetate loaded PLGA microspheres, physical mixture, polymer carrier and pure drug were analyzed using a DSC-821 differential scanning colorimeter (Mettletr Toledo, Germany). Samples of about $5 \mathrm{mg}$ were placed in $50 \mu \mathrm{l}$ perforated aluminum pans and sealed using $10^{\circ} \mathrm{C} / \mathrm{min}$ heating rate. The analysis was performed at heating rate $10^{\circ} \mathrm{C} / \mathrm{min}$ from $20^{\circ} \mathrm{C}$ to $280^{\circ} \mathrm{C}$ using dry nitrogen as the effluent gas.

\section{$X$-ray diffraction $(X R D)$}

X-ray diffraction pattern of the Goserelin acetate loaded PLGA microspheres, polymer and pure drug were analysed using a Equinox $3000 \mathrm{XRD}$ system equipped with $\mathrm{Cu}-\mathrm{Ka}$ radiation source $(40 \mathrm{kV}, 30$ $\mathrm{mA}$ ). The scans were recorded in the $2 \Theta$ angle range from $0^{\circ} \mathrm{C}$ to $40^{\circ} \mathrm{C}$.

\section{In vitro drug release}

The in-vitro drug release was performed in release media under sink conditions on shaker incubator at constant temperature $\left(37^{\circ} \mathrm{C}\right)$. The 40mg Goserelin acetate loaded PLGA microspheres were dispersed screw capped bottles containing $50 \mathrm{~mL}$ release media phosphate buffer $\mathrm{pH} 7.4$ were fixed onto the platform in water bath for shaking at $50 \mathrm{rpm}$ in shaker incubator. At the set points, $2 \mathrm{~mL}$ sample was removed by syringe for analysis through $0.45 \mu \mathrm{m}$ mdi nylon filters. Any microspheres drawn into the syringe filter were returned back by washing with $2 \mathrm{~mL}$ replacement fresh media (pH7.4) and supernatants was analysed by HPLC at $220 \mathrm{~nm}$.

\section{Drug Release kinetics}

The drug release profile of optimized formulation was fitted to various kinetics models. Zero-order, First-order and Higuchi's model to analyze the mechanism of the drug release from microspheres. ${ }^{22}$

\section{In vivo drug release}

The experimental protocol for in vivo studies were reviewed and approved by the Institutional Animal Ethics Committee. Healthy male Wistar rats weighing between $250 \mathrm{~g}$ and $280 \mathrm{~g}$ (Average age 8-10 weeks) were used. These rats were divided into two groups $(n=4)$. One group for injection of Goserelin acetate loaded RG505 microspheres (Formulation M3) and the other group for injection of Goserelin acetate loaded RG504H microspheres (Formulation M5) at a dose 1mg. Microspheres were suspended in diluent containing Sodium carboxymethyl cellulose and Polysorbate 20. The formulation was injected into the subcutaneously at buttock (back side the thigh region) using a 21-gauge needle. Blood samples were taken at 1 day before injection and then at $1 \mathrm{~h}, 6 \mathrm{~h}, 1 \mathrm{~d}$, $3 \mathrm{~d}, 7 \mathrm{~d}, 10 \mathrm{~d}, 14 \mathrm{~d}, 17 \mathrm{~d}, 21 \mathrm{~d}, 24 \mathrm{~d}, 28 \mathrm{~d}, 31 \mathrm{~d}$ and 35 days after injection. $0.5 \mathrm{~mL}$ of blood samples were withdrawn from the Retro-orbital plexus at predetermined time interval. All blood samples were collected in EDTA tubes and were immediately centrifuged. Plasma samples were frozen and stored at $-20^{\circ} \mathrm{C}$ until analysis. The drug content was determined by LC-MS/MS. ${ }^{23-26}$ All the animals' procedures approved by Animal Welfare Division, Government of India (ref no.: CPCSEA/IAEC/ P'Ceutics-34/2017-18/133. For ethical reasons all the animals were euthanized using carbondioxide gas chamber at the end of the study.

\section{In vitro and in vivo correlation (IVIVC)}

IVIVC is a predictive mathematical models used to describe the relationship between in vitro drug release behaviour of a formulation and relevant in vivo response. There are different levels of IVIVC that 
have been described in the regulatory agency guidance. ${ }^{27-29}$ Level A correlation is most desirable and most informative is point to point correlation. Fraction of absorption is calculated by deconvolution techniques using Wanger Nelson method.

\section{RESULTS}

Microsphere morphology

The morphology of the Goserelin acetate loaded PLGA microspheres using high resolution digital optical microscope and scanning electron microscopy, analysed the surface structure and cross section of the microspheres. The microparticles showed smooth nonporous surface with spherical shape as shown in Figure 2 and Figure 3 and homogenous drug distribution in microspheres as shown in cross section of microspheres (Figure 4).

\section{Particle size analysis}

Mean particle size (d 0.5) of Goserelin acetate microspheres was found to be from $116.78 \pm 2.05$ to $81.96 \pm 1.55 \mu \mathrm{m}$ and span value from $1.20 \pm 0.02$ to $1.08 \pm 0.05$ of microspheres prepared with PLGA 50:50 and $88.11 \pm 2.33 \mu \mathrm{m}$ and span value $1.15 \pm 0.022$ of microspheres prepared with PLGA75:25 (Table 2).

\section{Encapsulation efficiency}

Encapsulation efficiency of Goserelin acetate in microspheres was found to be between $90.85 \pm 1.11 \%$ to $95.50 \pm 1.73 \%$ as shown in Table 2 . The encapsulation efficiency for microspheres formulated with PLGA 50:50 and PLGA75:25 were almost similar, despite difference in their lactide content.Primary phase and continuous phase ratio 1:5 to produce the optimum particle size and to achieve better encapsulation efficiency.

\section{Inherent Viscosity of microspheres}

Inherent viscosity of PLGA 50:50 was found to be between 0.58 0.04 to $0.71 \pm 0.04 \mathrm{dL} / \mathrm{g}$ and PLGA $75: 25$ was found to be $0.96 \pm 0.03 \mathrm{dL} / \mathrm{g}$
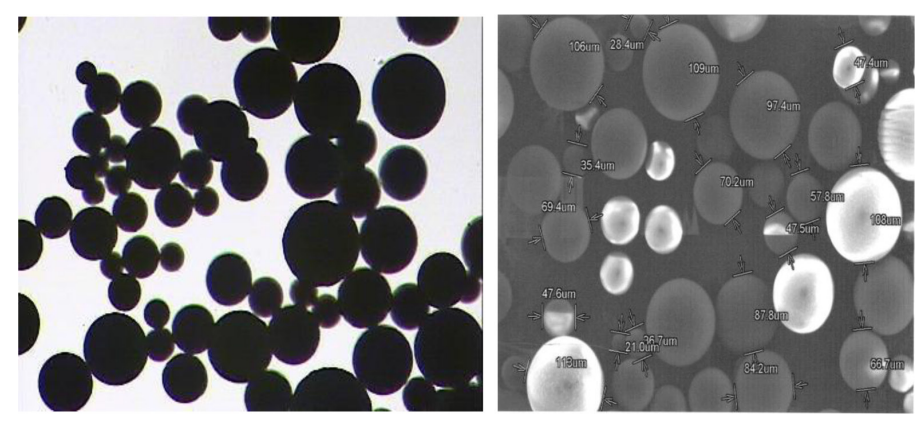

Figure 2: Optical microscopy photograph of microspheres.
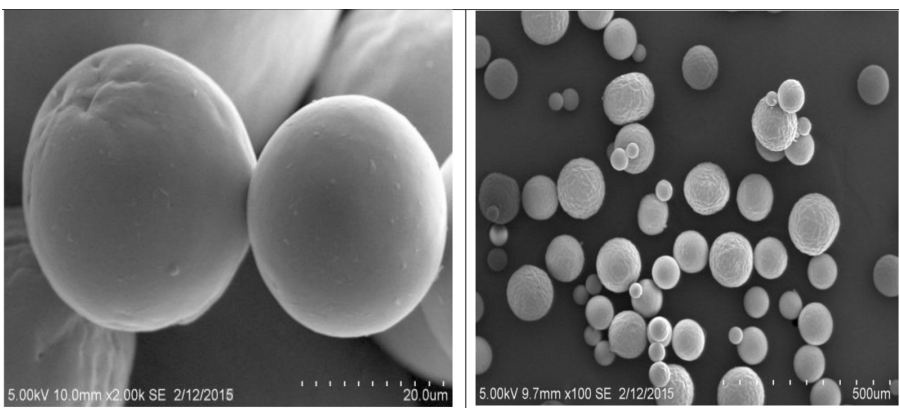

Figure 3: Scanning electron microscopy (SEM) of surface morphology microspheres.
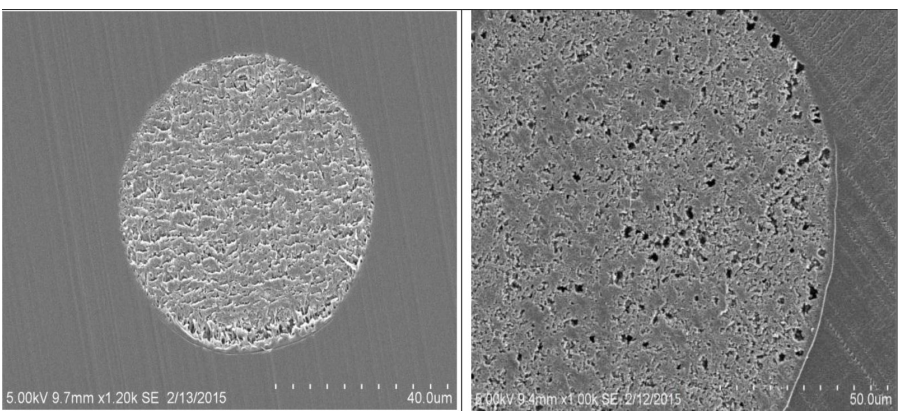

Figure 4: Scanning electron microscopy (SEM):Cross section/ Drug distribution of microspheres.

Table 2: Characterization of Polymer and Microspheres.

\begin{tabular}{|c|c|c|c|c|}
\hline $\begin{array}{c}\text { Formulation } \\
\text { Code }\end{array}$ & $\begin{array}{l}\text { Encapsulation } \\
\text { Efficiency (\%) } \\
\text { ( } \pm \text { SD) }\end{array}$ & $\begin{array}{l}\text { Inherent } \\
\text { Viscosity } \\
\text { (dl/gm) } \\
\text { ( } \pm \text { SD) }\end{array}$ & $\begin{array}{c}\text { Mean } \\
\text { Particle Size } \\
(\mu \mathrm{m}) \\
( \pm \mathrm{SD})\end{array}$ & $\begin{array}{c}\text { Span Value } \\
( \pm S D)\end{array}$ \\
\hline \multicolumn{5}{|c|}{ PLGA 50:50 } \\
\hline $\begin{array}{c}\text { Resomer } \\
\text { RG505 }\end{array}$ & - & $0.71 \pm 0.04$ & - & - \\
\hline M1 & $90.85 \pm 1.11$ & $0.59 \pm 0.01$ & $116.78 \pm 2.05$ & $1.20 \pm 0.02$ \\
\hline M2 & $92.45 \pm 1.32$ & $0.55 \pm 0.05$ & $102.77 \pm 2.11$ & $1.12 \pm 0.04$ \\
\hline M3 & $94.13 \pm 0.59$ & $0.60 \pm 0.02$ & $89.31 \pm 0.85$ & $1.11 \pm 0.02$ \\
\hline $\begin{array}{c}\text { Resomer } \\
\text { RG504 }\end{array}$ & - & $0.58 \pm 0.04$ & - & - \\
\hline M4 & $92.11 \pm 0.63$ & $0.48 \pm 0.02$ & $81.96 \pm 1.55$ & $1.08 \pm 0.05$ \\
\hline $\begin{array}{l}\text { Resomer } \\
\text { RG504H }\end{array}$ & - & $0.60 \pm 0.04$ & - & - \\
\hline \multirow[t]{2}{*}{ M5 } & $95.50 \pm 1.73$ & $0.53 \pm 0.03$ & $86.01 \pm 1.65$ & $1.13 \pm 0.03$ \\
\hline & & LGA 75:25 & & \\
\hline $\begin{array}{c}\text { Resomer } \\
\text { RG750 }\end{array}$ & - & $0.96 \pm 0.03$ & - & - \\
\hline M6 & $93.69 \pm 0.91$ & $0.79 \pm 0.01$ & $88.11 \pm 2.33$ & $1.15 \pm 0.02$ \\
\hline
\end{tabular}

were suitable for the microsphere formulations capable of degradation in 1 month and 3 month. Inherent viscosity of Goserelin acetate loaded PLGA 50:50 microspheres was found to be between $0.48 \pm 0.02 \mathrm{dL} / \mathrm{g}$ to $0.60 \pm 0.02 \mathrm{dL} / \mathrm{g}$ and Goserelin acetate loaded PLGA 75:25 was found to be $0.79 \pm 0.01 \mathrm{dL} /$ gas shown in Table 2 .

\section{Differential scanning colorimeter (DSC)}

DSC studies of PLGA, Goserelin acetate and Goserelin acetate loaded PLGA microspheres were performed. Thermogram of pure Goserelin acetate, PLGA 50:50 (Resomer RG505) and PLGA 75:25 (Resomer RG750) has sharp endothermic peak at $171.20^{\circ} \mathrm{C}, 40.56^{\circ} \mathrm{C}$ and $47.06^{\circ} \mathrm{C}$, which corresponds to its melting point (Figure 5). Thermogram of microspheres, the decrease in intensity of Goserelin acetate endothermic peak in drug loaded microspheres may be due partial conversion of crystalline to amorphous form. The DSC thermograms indicated that Goserelin acetate molecularly dispersed in microspheres.

\section{$X$-ray diffraction $(X R D)$}

X-ray diffraction (XRD) patterns of PLGA50:50 (Resomer RG505) and PLGA 75:25 (Resomer RG750), Goserelin acetate and Goserelin acetate loaded PLGA microspheres are shown in Figure 6 and Figure 7. Goserelin 


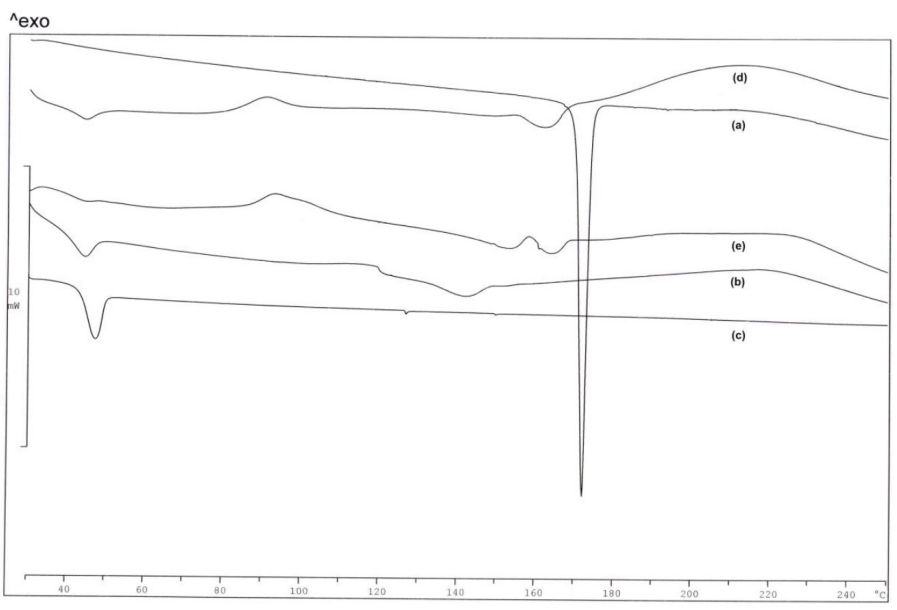

Figure 5: DSC Thermogram of (a) Goserelin acetate (b) PLGA 50:50 (c) PLGA 75:25 (d) Goserelin acetate PLGA 50:50 microspheres (e) Goserelin acetate PLGA 75:25 microspheres.

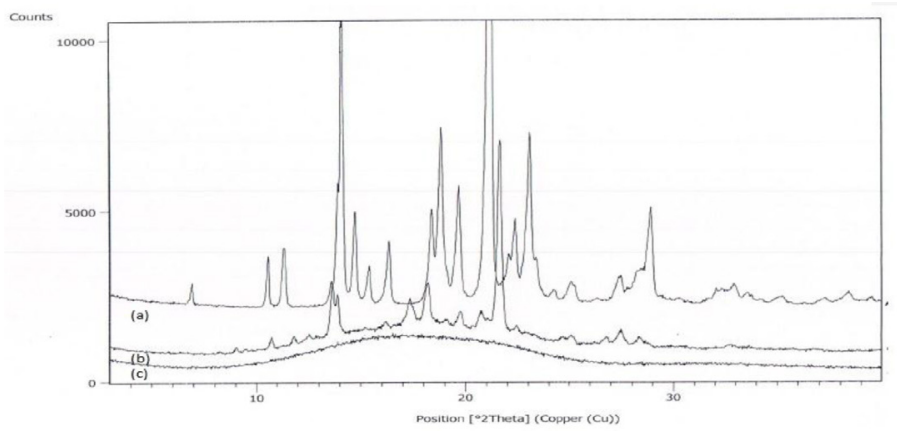

Figure 6: XRD of (a) Goserelin acetate (b) PLGA 50:50 (c) Goserelin acetate PLGA 50:50 microspheres.

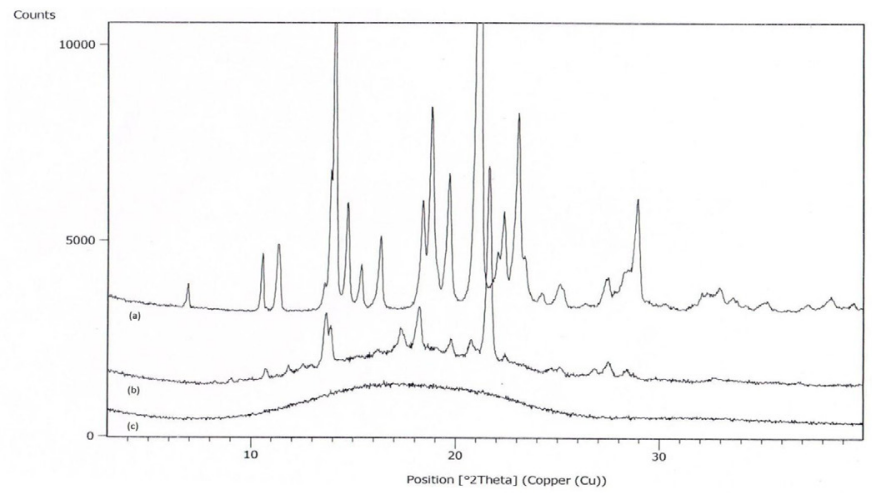

Figure 7: XRD of (a) Goserelin acetate (b) PLGA 75:25 (c) Goserelin acetate PLGA 75:25 microspheres.

acetate presence of $2 \Theta$ peaks values at $14.15^{\circ}, 18.47^{\circ}, 21.23^{\circ}, 23.11^{\circ}$, $28.92^{\circ}$ and $39.52^{\circ}$ indicated that crystalline form. The absence of these peaks in XRD patterns of Goserelin acetate loaded PLGA microspheres indicated that Goserelin acetate is amorphous form in the matrix of PLGA50:50 and PLGA 75:25.

\section{In vitro drug release}

Real time in vitro release profile of Goserelin acetate loaded PLGA microspheres were depicted in Figure 8. Drug released through M1, M2,
M3, M4 and M5 formulation containing PLGA 50:50, a burst release was observed within 1 day which was $25.63 \pm 3.91 \%, 21.23 \pm 1.39 \%$, $15.22 \pm 1.46 \%, 33.12 \pm 1.09 \%$ and $23.29 \pm 1.39 \%$ followed by a longer lag phase up to 14 days and erosion controlled release (plateau) $67.21 \pm$ $1.65 \%, 83.39 \pm 2.31 \%, 94.45 \pm 1.22 \%, 88.23 \pm 1.16 \%, 90.56 \pm 1.39 \%$ at the end of 30 days. Drug released through M6 formulation containing PLGA 75:25, where only $44.49 \pm 1.59 \%$ drug was released ate the end of 30 days.

\section{Drug Release Kinetics}

The above drug release data of optimized formulation M3 and M5 were fitted kinetics models Zero-order, First-order and Higuchi's model. The correlation coefficient of determination values as shown in Table 3. This result may indicate that the drug release mechanism was mainly due to the combination of diffusion of drug through the polymer and polymer erosion of the PLGA microspheres.

\section{In vivo drug release}

The optimized formulation Goserelin acetate loaded PLGA 50:50 microspheres, formulation M3 (Resomer RG505) and formulation M5 (Resomer RG 504H)microspheres were selected for in vivo study. The mean plasma concentration time profile of Goserelin acetate following subcutaneous administration of the Goserelin acetate loaded PLGA microspheres in rat model are shown in Figure 9 and Table 4. The plasma concentration of Goserelin acetate raised to the maximum concentration $\left(\mathrm{C}_{\max }\right)$ of formulation $\mathrm{M} 3$ and $\mathrm{M} 5$ were found to be $25.28 \pm 6.11 \mathrm{ng} / \mathrm{mL}$ and $37.69 \pm 6.51 \mathrm{ng} / \mathrm{mL}$ at $6 \mathrm{~h}\left(\mathrm{~T}_{\max }\right)$; then the decreased level steadily and maintained at value about $7.22 \pm 2.06 \mathrm{ng} / \mathrm{mL}$ to $8.59 \pm 1.22 \mathrm{ng} / \mathrm{mL}$ and $11.64 \pm 2.43 \mathrm{ng} / \mathrm{mL}$ to $13.17 \pm 1.62 \mathrm{ng} / \mathrm{mL}$ from day 3 to day 7 ; after that the plasma concentration of Goserelin acetate rise gradually, reaching a second maximum plasma level of $53.03 \pm 6.96 \mathrm{ng} / \mathrm{mL}$ and $61.69 \pm 2.86 \mathrm{ng} / \mathrm{mL}$ at the Day 14 , followed by a slowly decrease to below $0.50 \pm 0.22 \mathrm{ng} / \mathrm{mL}$ and $0.36 \pm 0.15 \mathrm{ng} / \mathrm{mL}$ at 35 Day. Thus, the duration of Goserelin acetate release from the PLGA 50:50 (Resomer RG505 and Resomer RG $504 \mathrm{H}$ ) microspheres was about one month. In addition, the area under the curve (AUC) of formulation M3 and M5 were found to be $13857 \pm 567.48 \mathrm{ng} . \mathrm{h} / \mathrm{mL}$ and $14515 \pm 708.1 \mathrm{ng} . \mathrm{h} / \mathrm{mL}$.

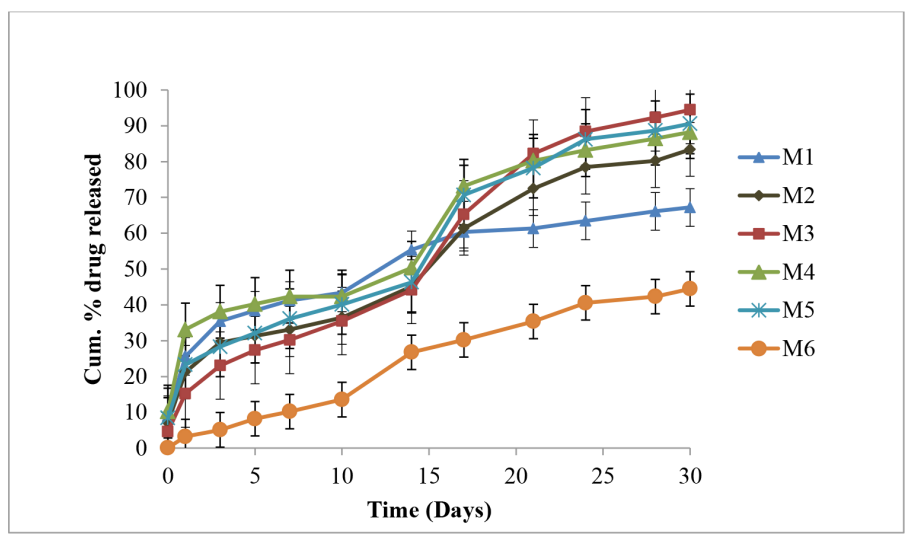

Figure 8: In vitro release behaviour of Goserelin acetate microspheres.

Table 3: Release kinetics studies of Goserelin acetate PLGA microspheres.

\begin{tabular}{ccccc}
\hline $\begin{array}{c}\text { Formulation } \\
\text { code }\end{array}$ & $\begin{array}{c}\text { Zero order } \\
\left(\mathbf{R}^{2}\right)\end{array}$ & $\begin{array}{c}\text { First order } \\
\left(\mathbf{R}^{2}\right)\end{array}$ & $\begin{array}{c}\text { Higuchi } \\
\text { model }\left(\mathbf{R}^{2}\right)\end{array}$ & $\begin{array}{c}\text { Korsemeyer- } \\
\text { Peppas }\left(\mathbf{R}^{2}\right)\end{array}$ \\
\hline M3 & 0.956 & 0.961 & 0.981 & 0.923 \\
M5 & 0.968 & 0.978 & 0.927 & 0.911 \\
\hline
\end{tabular}




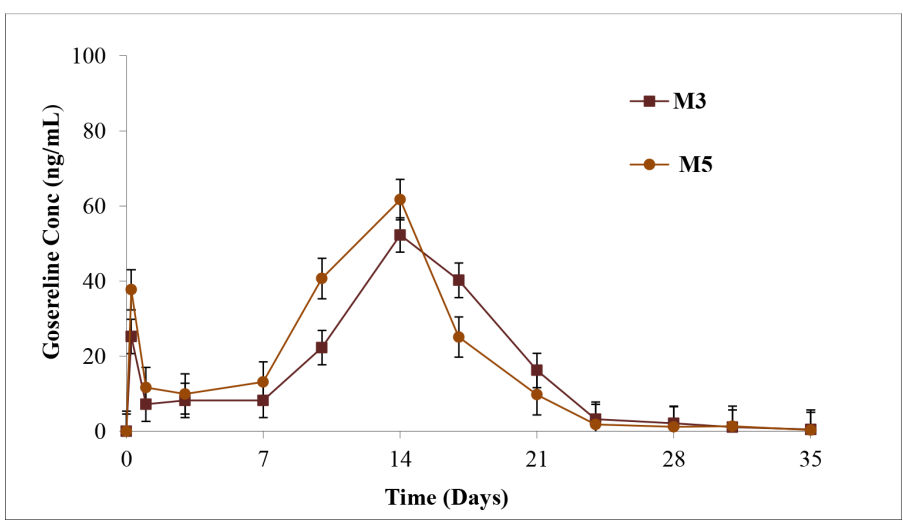

Figure 9: In vivo release behaviour of Goserelin acetate microspheres.

Table 4: Pharmacokinetic parameters of Goserelin acetate PLGA microspheres.

\begin{tabular}{cccc}
\hline $\begin{array}{c}\text { Formulation } \\
\text { code }\end{array}$ & $\mathrm{T}_{\max }($ Days $)$ & $\begin{array}{c}\mathrm{C}_{\max }(\mathrm{ng} / \mathrm{mL}) \\
( \pm \mathrm{SD})\end{array}$ & $\begin{array}{c}\mathrm{AUC}_{\text {last }}(\mathrm{ng} \cdot \mathrm{h} / \mathrm{mL}) \\
( \pm \mathrm{SD})\end{array}$ \\
\hline M3 & 14 & $53.03 \pm 6.96$ & $13857 \pm 567.48$ \\
M5 & 14 & $61.69 \pm 3.73$ & $14515 \pm 708.1$
\end{tabular}

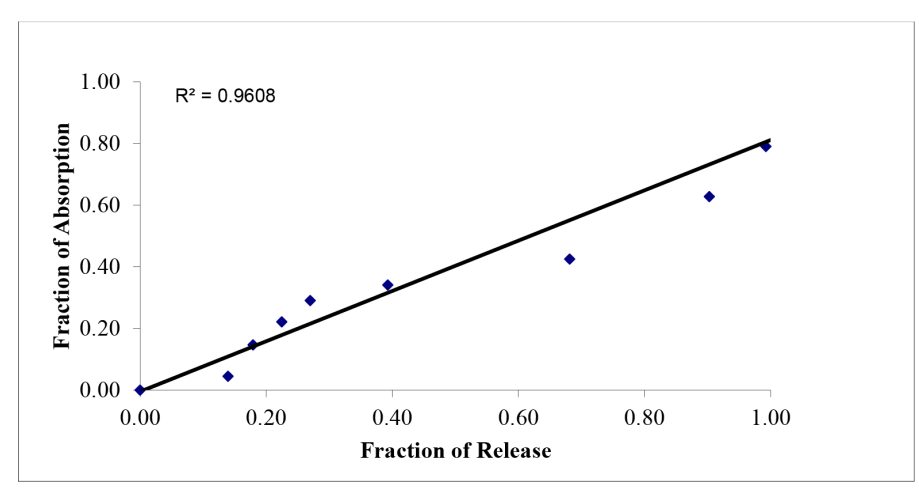

Figure 10: Correlation of Formulation M3 fraction of absorption in vivo Vs fraction of release in vitro.

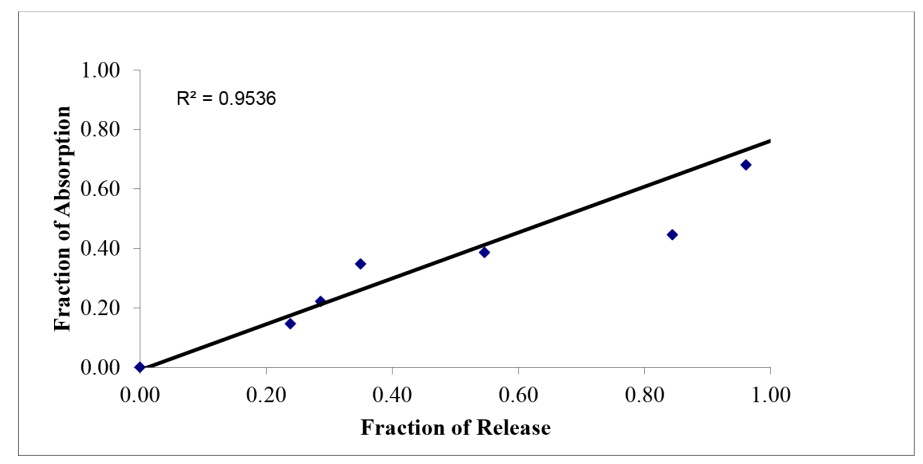

Figure 11: Correlation of Formulation M5 fraction of absorption in vivo Vs fraction of release in vitro.

\section{In vitro and in vivo correlation (IVIVC)}

The amount of the drug absorbed was determined using Wanger-Nelson. The cumulative percentage of the drug dissolved and cumulative fraction of the drug absorbed was plotted (Figure 10 and Figure 11). The correlation coefficient $\left(r^{2}\right)$ of M3 and M5 formulation were found to be 0.9608 and 0.9536. Thus it can be concluded that good IVIVC was observed and in vitro drug release test seemed to be rational anticipate in vivo release performance of Goserelin acetate loaded PLGA microspheres.

\section{DISCUSSION}

\section{Process variables}

The most suitable method for encapsulation of hydrophilic drug into PLGA microspheres is the double emulsion solvent extraction techniques. The drug Goserelin acetate, being water soluble, the solvent emulsification using static mixer method was selected. Multiple parameters exhibit that PLGA can easily be formulated into drug carrying devices as microspheres.

Morphologyandparticlesizeareimportantcharacteristicsofmicrospheres, because of its effect on degradation rate, drug loading and initial burst release of microspheres. ${ }^{30}$ The preparation of emulsion using static mixer, the particle size of the resulting microspheres can easily be controlled by the flow rates and ratio of primary phase and continues phase to be mixed. ${ }^{31}$ It was found that an increase the in the phases flow rates resulted in a decrease in microspheres mean size. These results findings may be explained on the basis of change in the viscosity of the primary and ternary emulsion formed during emulsification processing. Increase viscosity of the emulsion by alternation of primary emulsion and continuous phase ratio resulted in high viscous resistance against the shear force during the forming of microspheres. ${ }^{32}$ The external energy in the form of emulsification and the concentration of emulsifier in continuous phase causing droplet breakdown were kept constant; thus on increasing continuous phase volume, the same amount of energy must now be distributed in the large volume, resulting to less droplet breakdown and hence bigger microspheres were obtained. ${ }^{33}$

The porosity of the microspheres decreases with increasing continuous phase ratio and thus lower continuous phase ratio could have resulted in more porous microspheres leading to burst release, can probably be explained by the difference in the distribution of drug in microspheres due to different evaporation rates of the organic solvent. At lower continuous phase ratio, ethyl acetate will distribute into the continuous phase slowly, which is controlled byethylacetateevaporation rate; therefore, the drug will tend to migrate onto the microspheres surface together with ethyl acetate because of more solubility in the organic solvent, resulting in drug-rich microspheres surface. When the continuous phase ratio is high, ethyl acetate distributes in water quickly and the drug solidifies in the polymer matrix rapidly. The drug near the surface will diffuse out of the microspheres first, causing burst release. These findings are in agreement with the published research, where the effect of process and formulation variables on Goserelin acetate loaded PLGA microspheres 'internal morphology' was evaluated.

The encapsulation efficiency increase with increase in the polymer concentration, from the result it can be inferred that there is proper distribution of Goserelin acetate in microspheres. The encapsulation efficiency based on the fast polymer precipitation on the surface of the primary phase or dispersed phase can prevent loss into the continuous phase. Solidification of the primary phase or dispersed phase is delayed; the encapsulation efficiency becomes low because more drug are diffuse into the continuous phase. ${ }^{34}$

The cumulative amount of drug release up to 30 days increased with increasing concentration of continuous phase used in the preparation of microspheres. The difference in the release profiles due to difference in the surface morphology and particle size of microspheres. It has been reported that large amount of continuous phase results in faster precipitation of the polymer with a smoother and less porous surface of the microspheres. ${ }^{35}$ 


\section{Formulation variables}

The influence of PLGA polymer properties such as molecular weight, inherent viscosity, hydrophilicity and lactide/glycolide ratio on particle size, morphology, encapsulation efficiency, in vitro release study and in vivo release study of Goserelin acetate loaded PLGA microspheres were studied. PLGA50:50 Resomer RG505, Resomer RG504, Resomer RG504H and PLGA75:25 Resomer RG750 were used for this study. The particle size of Goserelin acetate loaded PLGA microspheres turned into specifically affected by the molecular weight of polymers. At consistent solvent volume in organic phase, the viscosity of the polymeric solution becomes proportional to the molecular weight of the polymer. Low viscosity polymer solution might be dispersed in the external aqueous phase to a more quantity than high viscosity polymer solution and consequently reduced the microspheres to smaller size. The Goserelin acetate loaded PLGA microspheres showed smooth nonporous surface with spherical shape, there were no significant differences in surface morphology of the microspheres between Resomer RG505, Resomer RG504, Resomer RG504H and Resomer RG750.

The encapsulation efficiency of Goserelin acetate was highly dependent on the molecular weight and hydrophilicity of PLGA polymers. Goserelin acetate encapsulation efficiency higher for Resomer RG505 and Resomer RG750 compared to Resomer RG504 and Resomer RG504H. This might be due to the higher viscosity of polymeric solution as result of high molecular weight of the polymer which could prevent the partitioning of Goserelin acetate into internal and external phase. Despite the difference in their lactide content, the encapsulation efficiency of Goserelin acetate microspheres formulated with Resomer RG505 and Resomer RG750 were almost similar may be this ratio does not affect the encapsulation efficiency of Goserelin acetate microspheres. The Resomer RG504H also exerted positive influence on encapsulation efficiency compared to Resomer RG504. This might be due to the strong interaction of carboxylic group present in polymer chain with the amine group of the drug molecules.

Higher inherent viscosity of PLGA (Resomer RG505 and Resomer RG750) resulted in longer lag times and less initial drug release because of the higher molecular weight of PLGA and thus slower PLGA degradation. ${ }^{36}$ The rapid release phase due to PLGA degradation was delayed as result of the longer lag time. PLGA polymers with low inherent viscosities have higher hydration and swelling properties, therefore leading to faster diffusion of surface-associated drug into the release medium.

DSC and XRD techniques were carried out as the useful tool in investigation of physicochemical properties of Goserelin acetate in microspheres formulation. The crystallinity changes of drug during microspheres formulation process clearly influence the drug release rate and bioavailability. ${ }^{37}$ The obtain DSC thermograms and their respective endothermic values indicated that the drug and manufacturing process had slight impact on the thermal properties of the polymer. These findings are highly consistent with the XRD results, that the dispersion of drug in the core of Goserelin acetate loaded PLGA microspheres leads to the crystalline Goserelin acetate molecules melting peak disappearance. Moreover, in view of the objective of the current formulation to provide a constant drug release, the molecular dispersion of Goserelin acetate in microspheres seems to give sustained release profiles for the intended drug delivery applications.

The in vitro release profile of microspheres are intended to help in predicting the final behavior of a given microspheres formulation. The release of Goserelin acetate from PLGA50:50 and PLGA75:25 showed different release properties. This might be due to difference in their lactide/glycolide ratio and higher content glycolide leads to faster degradation rate. The Resomer RG504 showed faster degradation rate and higher initial burst release compared to Resomer RG504H. This was attributed to the polymer terminal carboxylic group because hydrophilicity of polymer which cause favourable interaction between free carboxylic end group within the polymer chains and Goserelin acetate. It was noticeable that the polymer composition was very important factor to controlled release profile of Goserelin acetate from microspheres.

The mechanism of Goserelin acetate release from PLGA microspheres was investigated by correlation coefficient values and drug release was found to be controlled by diffusion of drug through polymer matrix. In vivo study the difference in the release profile of two formulation are easily discernible. Different plasma concentration of formulation with Resomer RG505 and Resomer RG504H were detected depending on the system which Goserelin acetate was released because different hydrophobic behavior of polymer. It indicates that sustainable release properties of Goserelin acetate loaded PLGA microspheres for treatment of hormone responsive cancers.

The IVIVC predictive can allow in vitro dissolution study as a substitute for in vivo study from controlled release dosage form. Result of the in vitro release showed that optimized formulation resulted in one month and complete release of the drug from the microspheres. Simple in vitro study may not however reflect the same in vivo effects. Hence, we also performed studies to determine drug release profile in vivo. Interestingly, the optimal formulation resulted in one month and complete release in vivo. In addition, also established IVIVC. This correlation was 100 percent suggesting that result from in vitro studies are valid.

\section{CONCLUSION}

In present study, Goserelin acetate was successfully encapsulated into PLGA microspheres by modified emulsification technique using static mixer. The results of this investigation explicate that the process and formulation variables could be effectively modified to achieve the desired characteristics, such as homogenous drug distribution, particle size distribution, surface morphology, encapsulation efficiency, controlled initial burst release, in vitro and in vivo drug release profile of Goserelin acetate loaded biodegradable polymeric microspheres.

\section{ACKNOWLEDGEMENT}

The authors wish to thank Wockhardt Research Centre, Aurangabad, India for providing constant support and enthusiasm to complete this work.

\section{CONFLICT OF INTEREST}

The authors declare that they have no competing interests.

\section{ABBREVIATIONS}

PLGA: Poly(DL-lactide-co-glycolic acid); PGA: Poly(glycolic acid); PLA: Poly(lactic acid); $\mathbf{K}_{\mathrm{cl}}$ : Rate of elimination; $\mathbf{K}_{\mathrm{a}}$ : Rate of absorption; USFDA: United States of Food and Drug Administration; LH: Luteinizing hormone; PVA: Polyvinyl alcohol; DSC: Differential scanning colorimeter; Tg: Glass transition temperature; XRD: X-ray diffraction; HPLC: High performance liquid chromatography; EDTA: Ethylene diamine tetraacetic acid; LC-MS/MS: Liquid chromatography with tandem mass spectrometry; IVIVC: In vitro and in vivo correlation.

\section{REFERENCES}

1. Yie WC, Senshang L. Drug Delivery: Controlled Release. In: Swarbik Jeds Encyclopedia of Pharmaceutical Technology, New York, USA: Informa Healthcare. 2007; 1082-100.

2. Lakshmi PK. Dissolution testing is widely used in the pharmaceutical industry for optimization of formulation and quality control of different dosage form. Pharma Info Net. 2010. 
3. Shargel L, Wu-Pong S, Yu A. Applied Biopharmaceutics and Pharmacokinetics. New York: McGraw-Hill. 2012;469-503.

4. Park K. The controlled drug delivery systems: past forward and future back. J Control Release.2014;190:3-8.

5. Prausnitz MR, Langer R. Transdermal drug delivery. Nat Biotechnol. 2008;26:1261-1268.

6. Sinha VR, Trehan A. Biodegradable microspheres for parenteral delivery. Crit Rev Ther Drug Carrier Syst. 2005;22(6):535-602.

7. Yang $\mathrm{C}, \mathrm{Wu} \mathrm{H}$, Wang J. Formulation and evaluation of controlled-release of steroidal saponins-loaded collagen microspheres. Material Tech. 2005;34(9):534-9.

8. Vyas SP, Khar KK. Targeted and controlled drug delivery, novel carrier system. New Delhi, India: CBS Publication and Distributors. 2002;81-121.

9. Singh RR, Lillard J. Nanoparticle-based targeted drug delivery. Exp Mol Pathol. 2009;86(3):215-23

10. Lu S, Jun Z, Li M, Hou W, Yin Y, Zhou C, et al. Improved liquid phase separation process for generating biodegradable microspheres loaded with high concentrations of drugs for tumor embolization. Polym Plast Technol Materials. 2018;58(9):1005-12.

11. Wischke C, Schwendeman SP. Principles of encapsulating hydrophobic drugs in PLA/PLGA microparticles. Int J Pharm. 2008;364(2):298-327.

12. Moinard-Checot D, Chevalier $Y$, Briancon S, Beney L, Fessi H. Mechanism of nanocapsules formation by the emulsion-diffusion process. J Colloid Interface Sci. 2008;317(2):458-68.

13. Yoon Y, Kinam P. Control of encapsulation efficiency and initial burst in polymeric microparticle systems. Arch Pharm Res.2004;27(1):1-12.

14. Dong N, Zhu C, Jiang J, Huang D, Li X, Quan G, et al. Development of composite PLGA microspheres containing exenatide-encapsulated lecithin nanoparticles for sustained drug release. Asian J Pharm Sci. 2019;42:1-9.

15. Etchells III AW, Meyer CF. Mixing in pipelines. Handbook of Industrial Mixing: Science and Practice. New York: Wiley Interscience. 2004;391-478.

16. Herington AC, Chopin LK, Jeffery P, Amorim LD, Veveris-Lowe T, Bui L, et al Hormone-dependent cancers: New approaches to identification of potential diagnostic and/ or therapeutic biomarkers. As Pac J Mol Biol Biotechnol. 2010;18(1):63-6

17. Cheng M, Michalski S, Kommagani R.. Role for growth regulation by estrogen in breast cancer 1(GREB1) in hormone-dependent cancers. Int $\mathrm{J}$ Mol Sci. 2018;19(9):2543

18. Kaufmann $M$, Jonat $W$, Kleeberg $U$, Eiermann $W$, Janicke $F$, Hilfrich $J$, et al. Goserelin, a depot gonadotrophin-releasing hormone agonist in the treatment of premenopausal patients with metastatic breast cancer. German zoladex trial group. J Clin Oncol. 1989;7(8):1113-9.

19. Oi P, Bu R, Zhang H, Yin J, Chen J, Zhang A, et al. Goserelin acetate loaded poloxamer hydrogel in PLGA microspheres: Core-shell di-depot intramuscular sustained release delivery system. Mol Pharm. 2019;16(8):3502-13.

20. Kiss N, Brenn G, Pucher H, Wieser J, Scheler S, Jennewein H, et al. Formation of OM emulsions by static mixers for pharmaceutical applications. Chem Engin Sci. 2011;66(21):5084-94.
21. Chen $Y$, Wang F, Benson HA. Effect of formulation factors on incorporation of the hydrophilic peptide dalargin into PLGA and MPEG-PLGA nanoparticles. Peptide Sci. 2008;90(5):644-50.

22. Bhasarkar J, Bal D. Kinetic Investigation of a controlled drug delivery system based on alginate scaffold with embedded voids. J Appl Biomater Funct Mater. 2019;17(2):1-8.

23. Ward JA, Robinson J, Furr BJ, Shalet SM, Morris ID. Protection of spermatogenesis in rats from the cytotoxic procarbazine by the depot formulation of zoladex, a gonadotropin-releasing hormone agonist. Cancer Res. 1990;50(3):568-74.

24. Cockshott ID. Clinical pharmacokinetics of goserelin. Clin Pharmacokine. 2000;39(1):27-48.

25. Horvath JE, Bajo AM, Groot K. Effect of long-term treatment with the luteinizing hormone-releasing hormone ( $\mathrm{LHRH})$ agonist decapeptyl and the $\mathrm{LHRH}$ antagonist certorelix on the levels of pituitary LHRH receptors and their mRNA expression in rats. PNAS. 2002;99(23):15048-53.

26. Xie $\mathrm{X}$, lin $\mathrm{W}$, Xing $\mathrm{C}$, Yang $\mathrm{Y}$, Chi Q, Zhang $\mathrm{H}$, et al. In vitro and in vivo evaluations of PLGA microspheres containing nalmefene. Plos One. 2015;10(5):1-19.

27. Food and drug administration. Central for drug evaluation and research, Guidance for industry bioanalytical method validation. 2018. http://www.fda gov/cder/guidance/4252fnl.pdf.

28. Chilukuri DM, Sunkara G, Young D. Pharmaceutical product development: in vitro-in vivo correlation. $1^{\text {st }}$ edn. New York: Informa Healthcare publishers. 2007;210-24.

29. Uppoor VR. Regulatory perspectives on in vitro (dissolution)/in vivo (bioavailability) correlations. J Control Release. 2001;72(1-3):127-32.

30. Yang $Y Y$, Chia HH, Chung TS. Effect of preparation temperature on the characteristics and release profiles of PLGA microspheres containing protein fabricated by double-emulsion solvent extraction/evaporation method. J Control Release. 2000;69(1):81-96.

31. Maa YF, Hsu CC. Effect of primary emulsion on microspheres size and proteinloading in the double emulsion process. J Microencapsul. 1997;14(2):225-41.

32. Quintanar-Guerrero D, Fessi H, Allemann E, Doelker E. Influence of stabilizing agents and preparative variables on the formation of poly (D, L-lactic acid) nanoparticles by an emulsification-diffusion technique. Int J Pharmaceutics. 1996;143(2):133-41.

33. Sharma N, Madan P, Lin S. Effect of process and formulation variables on the preparation of parenteral paclitaxel-loaded biodegradable polymeric nanoparticles: A co-surfactant study. Asian J Pharmaceu Sci.2016;11(3):404-16.

34. Freytag T, Dasheysky A, Tillman L, Hardee GE, Bodmeier R. Improvement of the encapsulation efficiency of oligonucleotide-containing biodegradable microspheres. J Control Release. 2000;69(1):197-207.

35. Choi HS, Seo SA, Khang G. Preparation and characterization of fentanyl-loaded PLGA microspheres: in vivo release profiles. Int J Pharma. 2002;234(1-2):195-203.

36. Alexis F. Factors affecting the degradation and drug-release mechanism of poly (lactic acid) and poly[(lactic acid)-co-(glycolic acid)]. Polymer Int. 2005;54(1):36-46.

37. Freiberg S, Zhu XX. Polymer microspheres for controlled drug release. Int J Pharm. 2004;282(1-2):1-18.

Article History: Submission Date : 15-02-2020; Revised Date : 14-03-2020; Acceptance Date : 07-04-2020.

Cite this article: Kakade SM, Hassan DM. Formulation and in vitro / in vivo Evaluation of Novel Biodegradable Microspheres for Treatment of Hormone Responsive Cancers. Int. J. Pharm. Investigation. 2020;10(2):183-91. 